\title{
p

\section{The use of embryonic cells in the treatment of osteochondral defects of the knee: an ovine in vivo study}

\author{
ANDREA FABIO MANUNTA ${ }^{1}$, PIETRO ZEDDE ${ }^{2}$, SUSANNA PILICCHI ${ }^{3}$, STEFANO ROCCA ${ }^{4}$, ROY R. \\ POOL $^{5}$, MARIA DATTENA ${ }^{3}$, GEROLAMO MASALA ${ }^{4}$, LAURA MARA ${ }^{3}$, SARA CASU $^{3}$, DANIELA SANNA ${ }^{3}$, \\ MARIA LUCIA MANUNTA ${ }^{4}$, ERALDO SANNA PASSINO ${ }^{4}$ \\ 1 Orthopaedic Department, University of Sassari, Italy \\ 2 Orthopaedic and Traumatology Unit, Hospital San Francesco, Nuoro, Italy \\ ${ }^{3}$ Department of Animal Science, Agricultural Research Agency of Sardinia Olmedo, Sassari, Italy \\ ${ }^{4}$ Department of Veterinary Medicine, University of Sassari, Italy \\ ${ }^{5}$ Department of Veterinary Pathobiology, College of Veterinary Medicine and Biomedical Sciences, Texas A\&M University, USA
}

\begin{abstract}
Purpose: the aim of this study was to determine whether local delivery of embryonic stem-like (ESL) cells into osteochondral defects in the femoral condyles of sheep would enhance regeneration of hyaline articular cartilage.
\end{abstract}

Methods: male ESL cells embedded in fibrin glue were engrafted into osteochondral defects in the medial condyles (ESL-M) of the left femur in 22 ewes. An identical defect was created in the medial condyle of the contralateral stifle joint and left untreated as a control (empty defect, ED). The ewes were divided into 5 groups. Four sheep each were euthanized at 1, 2, 6 , and 12 months from surgery, and 6 ewes were euthanized 24 months post-implantation. To study the effect of varying loads on the long-term regeneration process, an identical defect was also created and ESL cell engraftment performed in the lateral condyle (ESL-L) of the left stifle joint of the animals in the 12- and 24month groups. The evaluation of regenerated tissue was performed by biomechanical, macroscopic, histological, immunohistochemical (collagen type II) and fluorescent in situ hybridization (FISH) assays.

Results: no significant differences were found between treated and control sites in the biomechanical assays at any time point. ESL cell grafts showed signi-

\footnotetext{
Corresponding Author:

Andrea Fabio Manunta, PH

Orthopaedic Department, University of Sassari

Viale San Pietro 43/B, 07100 Sassari, Italy

E-mail: a.manunta@uniss.it
}

ficantly greater macroscopic evidence of regeneration as compared to controls at 24 months after surgery; significantly better histological evidence of repair in ESL-M samples versus controls was found throughout the considered period. At 24 months from surgery there was significantly improved integration of graft edges with the host tissue in the ESL-M as compared to the ESL-L samples, demonstrating that load bearing positively affects the long-term regeneration process. Conclusions: ESL cells enhanced the regeneration of hyaline cartilage. FISH confirmed that the regenerative tissue originated from ESL cells.

Clinical Relevance: ESL cells are able to self-renew for prolonged periods without differentiation and, most importantly, to differentiate into a large variety of tissues.

Keywords: articular cartilage, embryonic stem-like cell, osteochondral defect, sheep.

\section{Introduction}

Articular cartilage has a poor intrinsic capacity for repair because of its avascularity and very slow cellular and molecular turnover. As consequence, articular cartilage defects resulting from trauma or joint disease tend to be repaired with fibrocartilage rather than hyaline cartilage. Over time, degenerative processes frequently occur in the regenerated tissue, compromising the functionality of the joint $(1,2)$. The natural evolution of these degenerative processes is variable; lesions 
may stabilize or progress depending on three main factors: the depth, width and location of the defect. Superficial defects involving only articular cartilage do not heal spontaneously, probably because of the avascularity of this tissue, which results in a deficiency of the chondroprogenitor cells required for tissue regeneration and subsequent degeneration of the articular surface $(2,3)$; on the contrary, deeper osteochondral defects penetrate the subchondral bone, gaining access to the progenitor cells that reside in the bone marrow space (4-6). The width of the defect is also an important variable influencing the type of repair that will occur. It has been demonstrated, in sheep, that osteochondral defects with a width of $3 \mathrm{~mm}$ or less refill with normal hyaline cartilage, whereas wider defects are repaired with fibrocartilage (7). As the size of the defect reaches a critical diameter, beyond which healing is not possible, there is mechanical overloading along its periphery, which leads to subchondral plate destruction and substantial impairment of the regenerative process $(8$, 9). Better healing occurs if the defect is located on a weight-bearing area; the greater joint surface compression and motion occurring in these areas induces the bidirectional flow of solutes that is necessary to nourish the cartilage, stimulating the stepwise processes of cartilage and bone repair $(10,11)$.

Treatments used to stimulate cartilage regeneration, in most cases, only delay the onset of degenerative processes (12-15), hence the ongoing search for alternative solutions; in this context, stem cell engraftment is among the most advanced new technologies (16-20). The systemic or local delivery of stem cells may enhance cartilage repair or inhibit the progressive loss of joint tissue $(21,22)$.

The aim of this study was to determine whether local delivery of embryonic stem-like (ESL) cells into osteochondral defects in the femoral condyles of sheep would enhance regeneration of hyaline articular cartilage.

\section{Methods}

All experiments were conducted in accordance with the institutional animal care regulations and all procedures conformed to the National Institute of Health Guidelines for the Care of Laboratory Animals. Where not indicated otherwise, chemicals were purchased from Sigma-Aldrich (Milan, Italy).

\section{Experimental design}

Twenty-two Sardinian ewes, about 5.5 years old and weighing approximately $45 \mathrm{~kg}$, were divided into five groups to be euthanized at 1, 2, 6, 12 and 24 months post-surgery respectively. Each group comprised four sheep with the exception of the 24-month group; six sheep were assigned to this group to account for possible deaths during the study period (Tab. 1). All the animals were given a general health examination, routinely dewormed and had their claws inspected prior to the experimental surgery. Engraftments were performed as follows: surgical defects created in the medial femoral condyle of the left joint received $60 \mu \mathrm{l}$ of fibrin glue (Tissucol ${ }^{\mathbb{R}}$; Baxter International Inc., Deerfield, IL, USA) containing about 500,000-700,000 ESL cells (ESL-M engraftment) derived from 2-3 male ESL colonies. The Y-gene sequence was used as a marker to detect the ESL cells in the regenerated tissue of the female sheep. An identical defect was created in the medial condyle of the right femur of each ewe and left untreated (empty defect, ED) to serve as a control. To study the effect of varying loads on the long-term regeneration process, an identical defect

Table 1. Experimental design.

\begin{tabular}{|c|c|c|c|c|}
\hline \multirow{3}{*}{$\begin{array}{l}\text { Group } \\
1 \text { month } \\
\end{array}$} & \multirow{3}{*}{$\begin{array}{c}\mathbf{N}^{\circ} \text { of sheep } \\
4 \\
\end{array}$} & \multicolumn{3}{|c|}{ Treatment sites } \\
\hline & & \multicolumn{3}{|c|}{ Stifle joint Femoral condyle Treatment } \\
\hline & & \multirow[t]{2}{*}{ left } & \multirow{2}{*}{$\begin{array}{l}\mathrm{M}^{\mathrm{a}} \\
\mathrm{L}^{\mathrm{b}}\end{array}$} & \multirow{2}{*}{$\begin{array}{l}\text { ESM }^{\mathrm{c}} \\
\text { ESL }^{\mathrm{d}}\end{array}$} \\
\hline & & & & \\
\hline & & \multirow[t]{2}{*}{ right } & \multirow{2}{*}{$\begin{array}{l}\mathrm{M} \\
\mathrm{L}\end{array}$} & \multirow{2}{*}{$\begin{array}{c}\mathrm{ED}^{e} \\
- \\
\end{array}$} \\
\hline & & & & \\
\hline \multirow[t]{4}{*}{2 months } & 4 & \multirow[t]{2}{*}{ left } & \multirow{2}{*}{$\begin{array}{c}\mathrm{M} \\
\mathrm{L} \\
\end{array}$} & \multirow{2}{*}{$\begin{array}{l}\text { ESM } \\
\text { ESL }\end{array}$} \\
\hline & & & & \\
\hline & & \multirow[t]{2}{*}{ right } & \multirow{2}{*}{$\begin{array}{l}\mathrm{M} \\
\mathrm{L}\end{array}$} & \multirow{2}{*}{$\begin{array}{c}\text { ED } \\
-\end{array}$} \\
\hline & & & & \\
\hline \multirow[t]{4}{*}{6 months } & 4 & \multirow[t]{2}{*}{ left } & \multirow{2}{*}{$\begin{array}{c}\mathrm{M} \\
\mathrm{L}\end{array}$} & \multirow{2}{*}{$\begin{array}{l}\text { ESM } \\
\text { ESL } \\
\end{array}$} \\
\hline & & & & \\
\hline & & \multirow[t]{2}{*}{ right } & \multirow{2}{*}{$\begin{array}{l}\mathrm{M} \\
\mathrm{L}\end{array}$} & \multirow{2}{*}{$\begin{array}{c}\text { ED } \\
-\end{array}$} \\
\hline & & & & \\
\hline \multirow[t]{4}{*}{12 months } & 4 & \multirow[t]{2}{*}{ left } & \multirow{2}{*}{$\begin{array}{c}\mathrm{M} \\
\mathrm{L}\end{array}$} & \multirow{2}{*}{$\begin{array}{c}\text { ESM } \\
\text { ESL }\end{array}$} \\
\hline & & & & \\
\hline & & \multirow[t]{2}{*}{ right } & $\mathrm{M}$ & \multirow{2}{*}{$\begin{array}{c}\text { ED } \\
-\end{array}$} \\
\hline & & & $\mathrm{L}$ & \\
\hline \multirow[t]{5}{*}{24 months } & 6 & \multirow[t]{2}{*}{ left } & $\mathrm{M}$ & \multirow{2}{*}{$\begin{array}{l}\text { ESM } \\
\text { ESL }\end{array}$} \\
\hline & & & $\mathrm{L}$ & \\
\hline & & \multirow[t]{2}{*}{ right } & $\mathrm{M}$ & \multirow{2}{*}{ ED } \\
\hline & & & $\mathrm{L}$ & \\
\hline & Tot. 22 & & & Tot. 66 \\
\hline $\begin{array}{l}\text { edial; ' later } \\
\text { S-like engra } \\
\text { o treatment }\end{array}$ & $\begin{array}{l}\text { eral; }{ }^{c} \text { ES-like } \\
\text { aftment in the } \\
\text { it }\end{array}$ & $\begin{array}{l}\text { engraftm } \\
\text { e lateral fo }\end{array}$ & me & $\begin{array}{l}\text { horal condyl } \\
\text { ct; empty d }\end{array}$ \\
\hline
\end{tabular}


and engraftment process was performed in the lateral femoral condyle (ESL-L) of the left stifle joint in the animals belonging to the 12- and 24-month groups. Thus, a total of 54 samples were created: 22 ESL-M, 10 ESL-L and 22 ED (Tab. 1). The sheep were euthanized at 1, 2, 6, 12 and 24 months post-operatively and the condylar articular defects were examined grossly and harvested for microscopic examination.

\section{Selection of male embryos and ESL cell production and cha- racterization}

Liquid phase duplex polymerase chain reaction (PCR) was performed on approximately 90 in vitro produced and vitrified blastocysts at day 6-7 of culture (23) according to the technique of Mara et al. (24). Two pairs of primers were used. The first identified the sex-determining region Y-linked gene sequence (SRY) and was amplified in males only, producing a 301-base pair (bp) fragment. The second, inserted in the 1,114bp long sheep satellite region (Sheep SAT 1,114 DNA repeat unit), was amplified in both males and females, yielding a 216-bp fragment, and was used as positive control for the reaction. Male lamb fibroblasts were used as positive control, while sheep oviductal cells served as negative control. Amplification products (15 $\mu \mathrm{l})$ were analyzed on $2 \%$ agarose gel stained with ethidium bromide and observed under ultraviolet light.

The inner cell mass from each male embryo, numerically identified, was isolated by immunosurgery and separately cultured on a mouse fibroblast feeder layer for 5 to 6 days to obtain ESL colonies. These were characterized both immunocytochemically, by detection of surface antigens for staminality (SSEA-1, SSEA-3 and SSEA-4) (25), and by assessment of the gene expression of the Oct 4, Nanog, Sox 2 and Stat 3 genes (26). To assess the absence of differentiation towards germinal layers, cytokeratin (anti-cytokeratin-18), early mesoderm (Fe-C6), embryonic myosin (F1-652) and neural precursor cell (FORSE-1) specific primary monoclonal antibodies (mAbs), supplied by the Developmental Studies Hybridoma Bank (DSHB; University of Iowa, Iowa City, IA, USA), were used (25).

\section{Preparation of cells for engraftment and surgical procedures}

Two to three male ESL colonies were harvested from the Petri dish, disaggregated using $0.05 \%$ trypsin + $0.02 \%$ EDTA and vigorous pipetting, and pooled together in $500 \mu \mathrm{l}$ of Dulbecco's Modified Eagle
Table 2. Semi-quantitative scoring system for mascoscopic evaluation of regenerated cartilage defects at 1,2, 6, 12 and 24 months after surgery $(9=$ normal; $0=$ worst healing).

\begin{tabular}{|c|c|c|}
\hline Categories & Score & Qualifications \\
\hline \multirow[t]{4}{*}{ Surface appearance of repairing tissue } & 3 & $100 \%$ normal $^{a}$ \\
\hline & 2 & $>75 \%$ normal \\
\hline & 1 & $50-75 \%$ normal \\
\hline & 0 & $<50 \%$ normal \\
\hline \multirow[t]{4}{*}{ Percent area of defect filled } & 3 & $100 \%$ \\
\hline & 2 & $>75 \%$ \\
\hline & 1 & $50-75 \%$ \\
\hline & 0 & $<50 \%$ \\
\hline \multirow[t]{4}{*}{ Graft-recipient tissue integration } & 3 & $100 \%$ of perimeter \\
\hline & 2 & $>75 \%$ \\
\hline & 1 & $50-75 \%$ \\
\hline & 0 & $<50 \%$ \\
\hline
\end{tabular}

Medium (Gibco by Invitrogen, Carlsbad, CA, USA). After the cells had been counted using a Thoma chamber, they were centrifuged and about 500,000700,000 cells were embedded in $60 \mu \mathrm{l}$ of fibrin glue to be engrafted into the cartilage defects.

After sedation (diazepam $0.4 \mathrm{mg} / \mathrm{kg}$ IV) and epidural anesthesia, arthrotomy of the stifle joint was performed using a cranio-lateral approach and medial patellar dislocation. Identical defects were created on the weight-bearing surface of both the femoral condyles; all the defects had the same diameter $(6 \mathrm{~mm})$ and depth $(2 \mathrm{~mm})$ and involved the subchondral bone (osteochondral defects). Both defects created in the left knee, in the medial and lateral condyles respectively, received the ESL cells embedded in glue, while the defect in the medial condyle of the right knee was left untreated. After re-positioning of the patella, the joint was closed. Prophylactic antibiotic treatment and an antinflammatory agent $(40 \mathrm{mg} / \mathrm{kg} /$ day amoxicillin and $2 \mathrm{mg} / \mathrm{kg} /$ day ketoprofen) were administered for 5 days. All the animals were kept confined in small groups for 10 days, and were then allowed to roam freely on pasture for the rest of the study.

\section{Gross evaluation}

Immediately after euthanasia, the defects were photographed to allow assessment by two blinded observers. A semi-quantitative scoring system (Tab. 2) was used to assess the regenerated tissue and the values obtained were averaged. 


\section{Biomechanical analysis}

The Artscan 1000 Arthroscopic Cartilage Stiffness Tester (Artscan Medical Innovation, Helsinki, Finland) was used to measure the stiffness of the regenerated cartilage. To calibrate the instrument, an indentation test was first performed on healthy cartilage. By pressing the distal end of the instrument on the surface of the newly formed tissue for about one second, articular cartilage deformation was measured and recorded by software linked to the instrument.

\section{Sexing of engrafted ESL cells 1 month after surgery}

To confirm the ESL cell origin of the regenerated tissue, samples of the engraftments were taken aseptically from the 1-month group immediately after euthanasia.

\section{Histological procedures and evaluation}

Femoral condylar articular defects containing regenerated tissue, adjacent host cartilage and subchondral bone were harvested using a water-cooled circular saw. The tissue blocks were fixed in 10\% neutral-buffered formalin for 4 days and then placed in a decalcification solution (1:1 citric acid/formic acid solution) for 4-10 days. After washing in running tap water for 4-8 $\mathrm{h}$ to remove all traces of decalcification solution, the samples were processed according to routine procedures for paraffin embedding. Three- $\mu \mathrm{m}$ sections were mounted on positively charged slides (Superfrost Plus; Gerhard Menzel GmbH, Braunschweig, Germany) to prevent detachment, and stained with hematoxylin-eosin to evaluate general tissue morphology, with Azan-Mallory staining to demonstrate collagen fibers and Safranin-O staining to reveal the presence and distribution of proteoglycans. All slides were processed together to avoid variability. Two independent observers evaluated the regeneration progress using a grading system derived from Caplan et al. (27) and the two values obtained for each sample were averaged. A total score of 5 indicated the worst possible healing, while 56 indicated the best.

\section{Immunobistochemistry}

Immunohistochemistry was used to detect type II collagen in the cartilage matrix. Deparaffinization through xylene and hydration through alcohol at different concentrations were followed by antigen unmasking by protease $\mathrm{K}$ digestion. After Tissue-Blocker (Biomeda Corp., Foster City, CA, USA) treatments, the slides were incubated overnight at $4{ }^{\circ} \mathrm{C}$ with a primary antibody (anti-Collagen type II CIICI-DSHB), followed by a secondary biotinylated antibody (Biomeda Corp.) for $10 \mathrm{~min}$ at room temperature (RT), and then 3\% peroxidase solution for $10 \mathrm{~min}$ at RT. After staining with diaminobenzidine (Biomeda Corp.) and counterstaining with hematoxylin, slides were dehydrated, coverslipped, and observed under light microscopy; digital images were captured. The right lateral femoral condyle was used as a positive (articular cartilage) and negative (subchondral bone) control.

\section{Fluorescent in situ bybridization (FISH) procedure}

To detect ESL cells in the regenerated tissue, a FISH assay was performed on one sample from each time point according to the method of Sanna et al. (28), using the 50-bp oligonucleotide DNA probe (5'AAAGGGAGGGAGAGACCAAAGAAGTAGATGATGATGATGATGAAGTGATC 3') built on the Ovisaries Y chromosome repeat region OY 11.1 DNA sequence. Tissues were examined with a fluorescent confocal microscope (Leica TCS SP 5, MIC DMI 6000, Leica Lasertechnick GmbH, Heidelberg, Germany) and images were recorded. All slides were processed together, including the right lateral femoral condyle as a negative control.

\section{Statistical analysis}

Statistical analysis was performed both on macroscopic and histological data. Two analyses were planned: the first comparing the ESL-M and ED samples both as a sum of all scores throughout all the considered periods (from 1 to 24 months) and within each single period (1, 2, 6, 12 and 24 months); the second comparing the ESL-M, ESL-L and ED samples both as a sum of all scores from the 12- and the 24-month groups and within the 12- and 24-month groups.

Each ewe served as its own control because each had both ESL cell engraftments and an ED. To evaluate the effect of time from surgery, treatment and the interaction between time and treatment on the tissue regeneration process, an analysis of variance was performed, where the variables were the total macroscopic score, the total histological score and the scores of several representative macroscopic and histological categories. The level of significance was $\mathrm{p}<0.05$. The GLM procedure of SAS 8.2 (SAS Institute Inc., Cary, NC, USA) was used to perform the analyses. 


\section{Results}

Eight sheep were moderately lame in both hind limbs the day after surgery, but they all walked normally by day 9. No further problems with locomotion were noted in any of the animals during the remainder of the study.

Of the 22 animals used in the study, only 17 were ultimately included in the statistical analysis. Three sheep, one each from the 1-, 2- and 24-month groups, died from toxemic gastroenteritis. The sheep belonging to the 24-month group died at about 12 months postsurgery, and hence data from this animal were included with the 12-month group. Three other sheep, belonging to the 1-, 6- and 24-month groups, sustained leg fractures (unrelated to the experimental procedures). Analyses were thus performed on the following animals: two sheep in the 1-month group, three in the 2-month group, three in the 6-month group, five in the 12-month group, and four in the 24-month group. Two samples per animal belonging to the 1-, 2and 6-month groups - one sample from the engraftment site of ESL cells in the medial condyle (ESL-M) and one from the empty defect (ED) - were analyzed. Three samples per animal in the 12- and 24-month groups - one ESL-M sample, one sample from the engraftment site of ESL cells in the lateral condyle (ESL-L), and one sample from the ED - were analyzed. We therefore analyzed a total of 43 samples: 17 ESL-M, 9 ESL-L and 17 ED.

\section{ESL cell production and characterization}

PCR sexing allowed selection of male embryos for production of male ESL cells. Male embryos showed two bands corresponding to SRY and SAT sequences, while female embryos showed only one band, corresponding to the autosomal sequence.

Immunocytochemical analysis demonstrated the staminality of ESL cells by positive staining for SSEA $\mathrm{mAbs}$ and positive gene expression for Oct 4, Nanog, Sox 2 and Stat 3 genes, and their undifferentiated state by the absence of staining with any of the anti-cytokeratin-18, Fe-C6, F1-652 and FORSE-1 mAbs.

\section{Gross evaluation}

When the sums of the ESL-M and ED sample scores for all the periods considered (from 1 to 24 months) were compared, no statistically significant differences were found, either in the total macroscopic score or in the single category scores (surface appearance, filling of defect, and edge integration) (Fig. 1).

Statistical analysis comparing the ESL-M and ED sample scores within each period could not be performed in the 1-, 2- and 6- month groups because of an insufficient number of samples. No significant differences in total macroscopic score, surface appearance, filling of the defect, or edge integration were found between ESL-M and ED at either 12 or 24 months (Fig. 1).

When the summed ESL-M, ESL-L and ED sample scores for the period 12 to 24 months were compared, no statistically significant differences in total macroscopic score, surface appearance, filling of defect or edge integration were found between the treatments (Figs. 1, 2).

When the ESL-M, ESL-L and ED scores at 12 months were compared, no statistically significant differences either in the total macroscopic score or in the single categories (surface appearance, filling of defect, or edge integration) were found between the treatments. At 24 months we found statistically significant improvements $(\mathrm{p}<0.01)$ in ESL-L vs ED in the variables total macroscopic score, surface appearance and

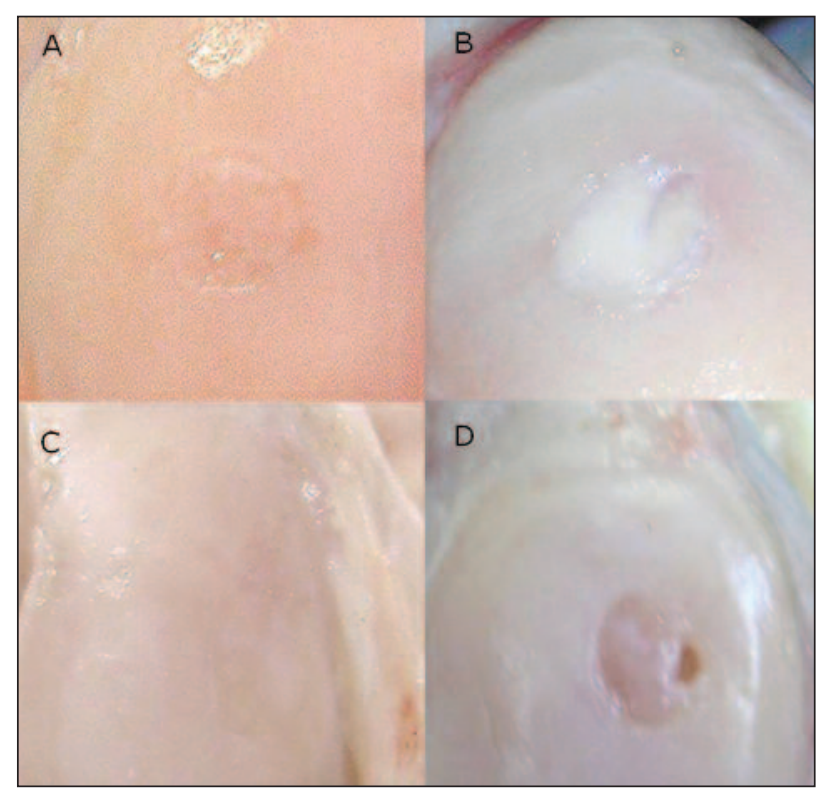

Fig. 1. Femur, sheep. Macroscopic appearance. Embryonic stem-like cell engraftment in the medial femoral condyle (ESL-M) and empty defect (ED) 12 and 24 months after surgery. A: ESL-M 12 months after surgery. B: ESL-M 24 months after surgery. C: ED 12 months after surgery. D: ED 24 months after surgery. 


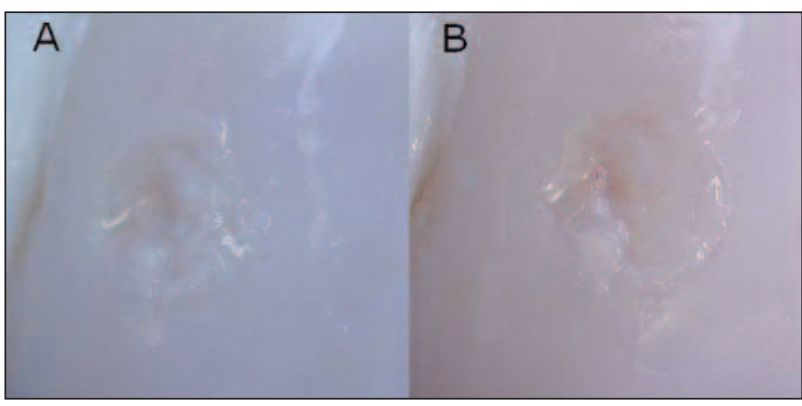

Fig. 2. Femur, sheep. Macroscopic appearance. Embryonic stem-like cell engraftment in the lateral femoral condyle (ESL-L) 12 and 24 months after surgery. A: ESL-L 12 months after surgery. B: ESL-L 24 months after surgery.

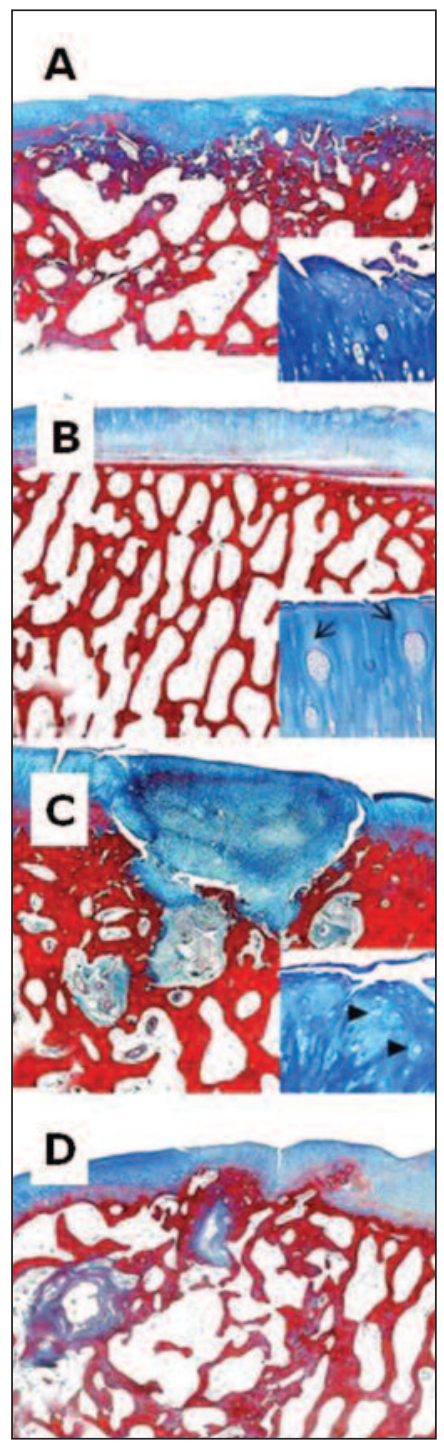

Fig. 3. Femur, sheep. Histological section, Azan-Mallory Staining. $2 X$ magnification; bar: $1 \mathrm{~mm}$. A: ESL-M tion; bar: 1 im. A: ESLengraftment 12 months afte surgery. B: ESL-M engraftment 24 months after surgery. C: ED 12 months after surgery. D: ED 24 months after surgery. filling of the defect. No significant difference in edge integration was found between the ESL-M, ESL-L and ED samples (Figs. 1, 2).

\section{Biomechanical analysis}

Samples collected from the $1^{\text {st }}$ through the $6^{\text {th }}$ month post-surgery showed incompletely filled cavities and, thus, the rod of the indenter could not reach the surface of the regenerating tissue to measure its stiffness. No significant differences were found at 12 months between ESL grafts and ED samples, although one ESL sample did have a slightly higher score. At 24 months after surgery all samples were classified as hard-flexible.

PCR sexing of ESL cell engraftments at 1 month post-surgery The PCR sexing confirmed that the cells present in the newly formed tissue were male and thus, derived from engrafted ESL cells. All tissue samples obtained from engraftments in the 1-month group showed two bands: amplification of SRY-specific primers produced a 301-bp fragment, while SAT-specific primers yielded a 216-bp fragment. Male lamb fibroblasts and sheep oviductal cells, used as positive and negative controls respectively, confirmed the results.

\section{Histological evaluation}

Comparison of the sums of the ESL-M and ED scores for all the periods considered (from 1 to 24 months) showed that the ESL-M samples showed a significantly higher $(\mathrm{p}<0.001)$ total histological score as compared to the ED ones. The ESL-M samples also scored significantly higher $(\mathrm{p}<0.05)$ in the following categories: filling of defect, cartilage, matrix, bone, edges (Figs. 3, 4).

Likewise, when the total histological scores for ESL$\mathrm{M}$ and ED were compared at 12 and at 24 months, a significantly higher score was found in the ESL-M samples at both time periods $(\mathrm{p}<0.05$ and $\mathrm{p}<0.01$, respectively). Edges were also significantly better integrated in the ESL-M samples at both 12 and 24 months ( $\mathrm{p}<0.05$ and $\mathrm{p}<0.01$, respectively) as compared to the ED ones (Tab. 3; Figs. 3, 4).

When the sums of ESL-M, ESL-L and ED scores for the period 12 to 24 months were compared, a significantly higher $(\mathrm{p}<0.01)$ total histological score was seen in the ESL-M vs ED as well as in the ESL-L vs ED $(p<0.05)$ samples. Scores were also significantly 
higher in the ESL-L vs ED samples for the categories matrix and bone $(\mathrm{p}<0.05)$ and in ESL-M vs ED for the categories edges and degeneration $(p<0.01$ and $p$ $<0.05$, respectively) (Figs. 3-5).

When the ESL-M, ESL-L and ED scores were compared at 12 months and at 24 months, a significantly higher total histological score was seen at 12 months in the ESL-L vs ED samples ( $p<0.05)$. Likewise, at 12 months, the ESL-L samples showed significantly higher scores in the category bone than the ESL-M (p $<0.05)$ and ED ( $\mathrm{p}<0.01)$ samples. Vascularity scores were significantly higher at 12 months in ESL-M vs ED ( $p<0.01)$. At 24 months, the ESL-M samples had significantly better total histological $(\mathrm{p}<0.05)$ and edges $(p<0.01)$ scores than the ED samples. The ESL$\mathrm{M}$ samples also had a significantly higher edges score $(\mathrm{p}<0.05)$ than the ESL-L ones (Tab. 4, Figs. 3-5).

\section{Immunohistochemistry}

At 1 month, cartilage matrix was negative for type II collagen immunostaining. At 2 months mild collagen type II immunostaining was detected around the chondroblasts arising from the bottom of the defect in one sample from each treatment. At 6 months, staining was marked in two ESL-M samples and 1 ED sample and moderate in the others. At 12 months, it was marked in most ESL-M, all ESL-L and three ED samples. By 24 months it was marked in most ESL-M and ESL-L samples and in one ED sample, while it was moderate in one ESL-M, one ESL-L and two ED samples, and absent in one ED sample (Fig. 6).

Fluorescent in situ bybridization (FISH) procedure

Dot-Blot showed positive spots with both DNA ESL cell samples and male fibroblasts (positive control), whereas female fibroblasts (negative control) were negative, confirming the specificity of the chosen probe. FISH showed positive intranuclear signals only in the ESL cells found in the newly formed tissue at all time points, while controls were always negative (Fig. 7).

\section{Discussion}

The repair of defects of articular cartilage with healthy hyaline cartilage continues to be a challenge (29). In this study, osteochondral defects created in both medial and lateral femoral sheep condyles were engrafted with ESL cells to evaluate their influence on the regeneration process.

ESL cell engraftments in the medial condyle (ESL-M) showed a significantly better healing process compared to what was observed in the contralateral EDs. In one animal at 12 months and in two animals at 24 months post-surgery, regenerated tissue appeared comparable to normal hyaline cartilage. In addition, at 24 months

Table 3. Least square means \pm standard error of histological scores in ESL-M and ED samples compared at 12 and at 24 months.

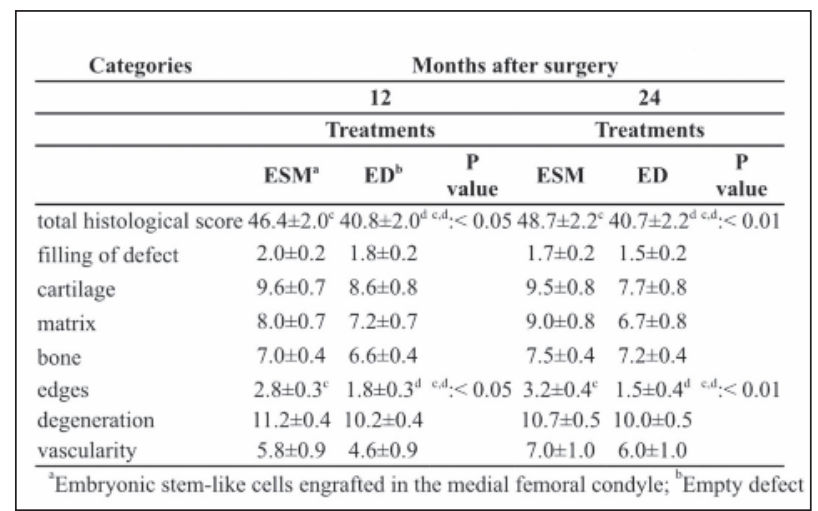

Table 4. Least square means \pm standard error of histological scores in ESL-M, ESL-L and ED samples compared at 12 and at 24 months.

\begin{tabular}{|c|c|c|c|c|c|c|c|c|}
\hline \multirow[t]{4}{*}{ Categories } & \multicolumn{8}{|c|}{ Months after surgery } \\
\hline & \multicolumn{4}{|c|}{12} & \multicolumn{4}{|c|}{24} \\
\hline & \multicolumn{4}{|c|}{ Treatments } & \multicolumn{4}{|c|}{ Treatments } \\
\hline & ESM $^{a}$ & ESL" & $\mathbf{E D}^{\mathrm{r}}$ & $\begin{array}{c}P \\
\text { value }\end{array}$ & ESM & ESL & ED & $\begin{array}{c}P \\
\text { value }\end{array}$ \\
\hline \multicolumn{9}{|c|}{ total histological score $46.4 \pm 2.348 .9 \pm 2.3^{d} 40.8 \pm 2.3^{\text {e dee }}<0.0548 .7 \pm 2.5^{d} 44.5 \pm 2.540 .7 \pm 2.5^{\text {ed } d . e i}<0.05$} \\
\hline filling of defect & $2.0 \pm 0.2$ & $2.0 \pm 0.2$ & $1.8 \pm 0.2$ & & $1.7 \pm 0.2$ & $1.7 \pm 0.2$ & $1.5 \pm 0.2$ & \\
\hline cartilage & $9.6 \pm 0.7$ & $9.2 \pm 0.7$ & $8.6 \pm 0.7$ & & $9.5 \pm 0.8$ & $8.5 \pm 0.8$ & $7.7 \pm 0.8$ & \\
\hline matrix & $8.0 \pm 0.7$ & $8.6 \pm 0.7$ & $7.2 \pm 0.7$ & & $9.0 \pm 0.8$ & $9.0 \pm 0.8$ & $6.7 \pm 0.8$ & \\
\hline bone & $7.0 \pm 0.4^{\mathrm{d}}$ & $7.6 \pm 0.4^{e}$ & $6.4 \pm 0.4^{f}$ & $\begin{array}{l}\text { d.e: }<0.05 \\
\text { e.f. }<0.01\end{array}$ & $7.5 \pm 0.4$ & $7.5 \pm 0.4$ & $7.2 \pm 0.4$ & \\
\hline edges & $2.8 \pm 0.4$ & $2.6 \pm 0.4$ & $1.8 \pm 0.4$ & & $3.2 \pm 0.5^{\mathrm{d}}$ & $2.0 \pm 0.5^{c}$ & $1.5 \pm 0.5^{f}$ & $\begin{aligned} \text { d.e: } & <0.05 \\
\text { d.f } & <0.01\end{aligned}$ \\
\hline degeneration & $11.2 \pm 0.4$ & $11.0 \pm 0.4$ & $10.2 \pm 0.4$ & & $10.7 \pm 0.5$ & $10.0 \pm 0.5$ & $10.0 \pm 0.5$ & \\
\hline vascularity & $5.8 \pm 1.0^{\mathrm{d}}$ & $8.0 \pm 1.0$ & $4.6 \pm 1.0^{e}$ & d.e: $<0.01$ & $7.0 \pm 1.1$ & $5.7 \pm 1.1$ & $6.0 \pm 1.1$ & \\
\hline
\end{tabular}



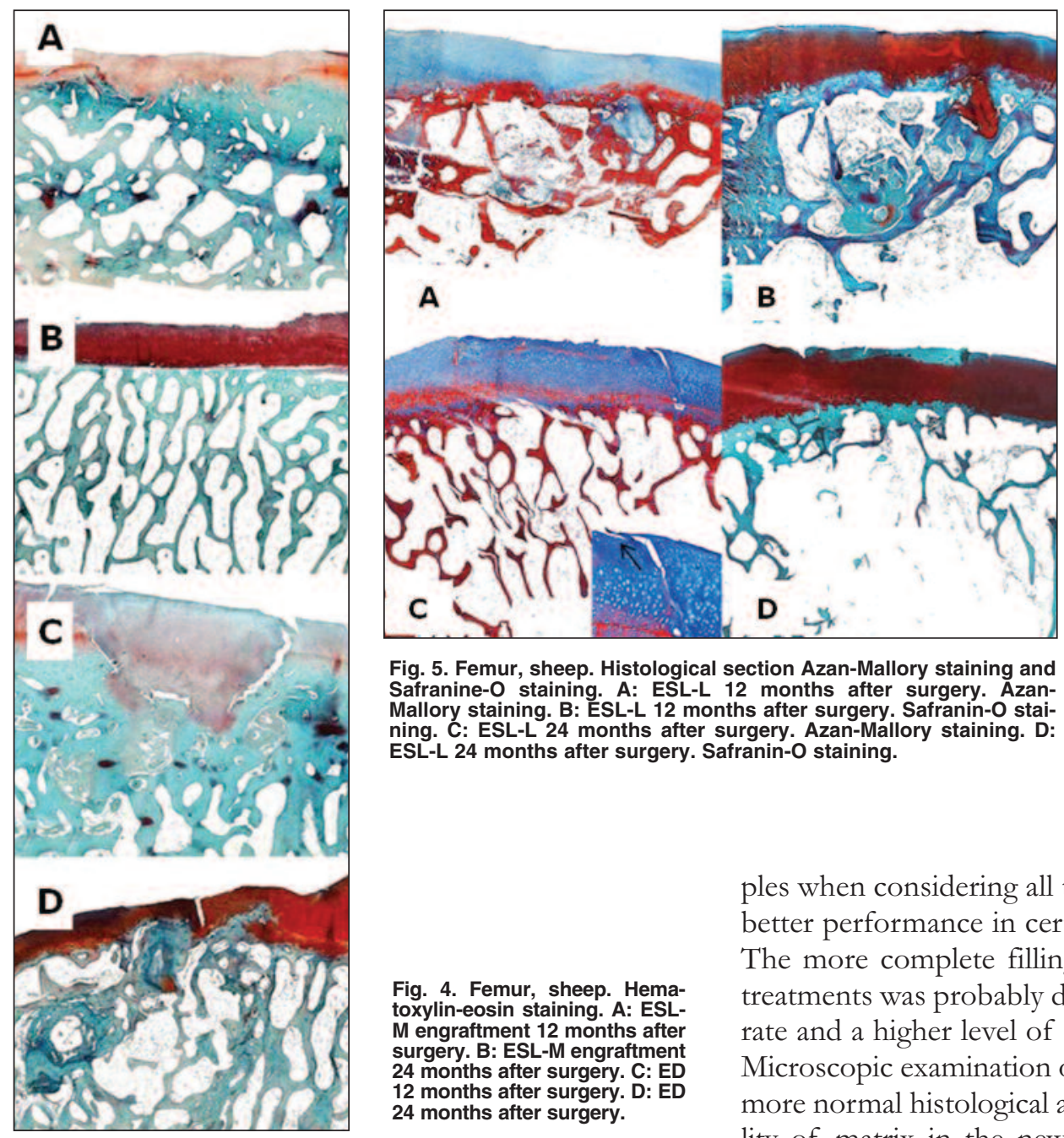

Fig. 5. Femur, sheep. Histological section Azan-Mallory staining and Safranine-O staining. A: ESL-L 12 months after surgery. AzanMallory staining. B: ESL-L 12 months after surgery. Safranin-O staining. C: ESL-L 24 months after surgery. Azan-Mallory staining. D. ESL-L 24 months after surgery. Safranin-O staining.

Fig. 4. Femur, sheep. Hematoxylin-eosin staining. A: ESL$M$ engraftment 12 months after $M$ engraftment 12 months after
surgery. B: ESL-M engraftment 24 months after surgery. C: ED 12 months after surgery. D: ED 24 months after surgery.

ESL-M samples showed better integration of edges as compared to what was observed in ESL cell engraftments in the lateral condyle (ESL-L).

The finding that ESL colonies were positive for SSEA mAbs and gene expression for Oct 4, Nanog, Sox 2 and Stat 3 genes, and negative for all the mAbs indicating the differentiated state, demonstrated that the engrafted cells were real stem cells. The suffix -like is used because of their early in vitro differentiation, a common limit of embryonic stem cells derived from ungulates (25).

Only embryos identified as males were used to produce ESL cells. Subsequent PCR sexing of ESL cell engraftments at 1 month after surgery confirmed that the cells present in the newly formed tissue were male and, therefore, derived from the implanted ESL cells. Thus, the choice of SRY as a marker for ESL cells was shown to be effective and reliable for this purpose.

In the gross evaluation, significant differences were detected only between ESL-L and ED samples at 24 months. This could be due to limits of the grading scores used.

Transverse sections to evaluate the quality of the newly formed tissue deep in the samples, or the presence of subchondral cysts, were not assessed.

The histological results showed better overall healing in ESL-M as compared to ED samples when considering all the time periods, as well as a better performance in certain specific categories.

The more complete filling of the defect in the ESL treatments was probably due to a faster cell replication rate and a higher level of metabolic activity.

Microscopic examination of ESL-M samples showed a more normal histological architecture and a better quality of matrix in the newly formed cartilage at each time point. This healed cartilage was comparable to normal hyaline cartilage in one animal at 12 months and in two animals at 24 months. It consisted of a superficial zone with proliferating germinal cells and collagen fibers distributed parallel to the articular surface and a transitional zone characterized by palisading chondrocytes and spring-shaped arrangements of collagen fibers. Subjacent to this was a radial zone with hypertrophic chondrocytes and collagen fibers arranged perpendicular to the articular surface, and a deep zone with calcification and formation of a discontinuous tidemark. The presence of the tidemark is an important finding; it has been reported (30) that this calcification front is in a state of dynamic equilibrium, where factors promoting mineralization are probably counterbalanced by substances that inhibit or limit the 


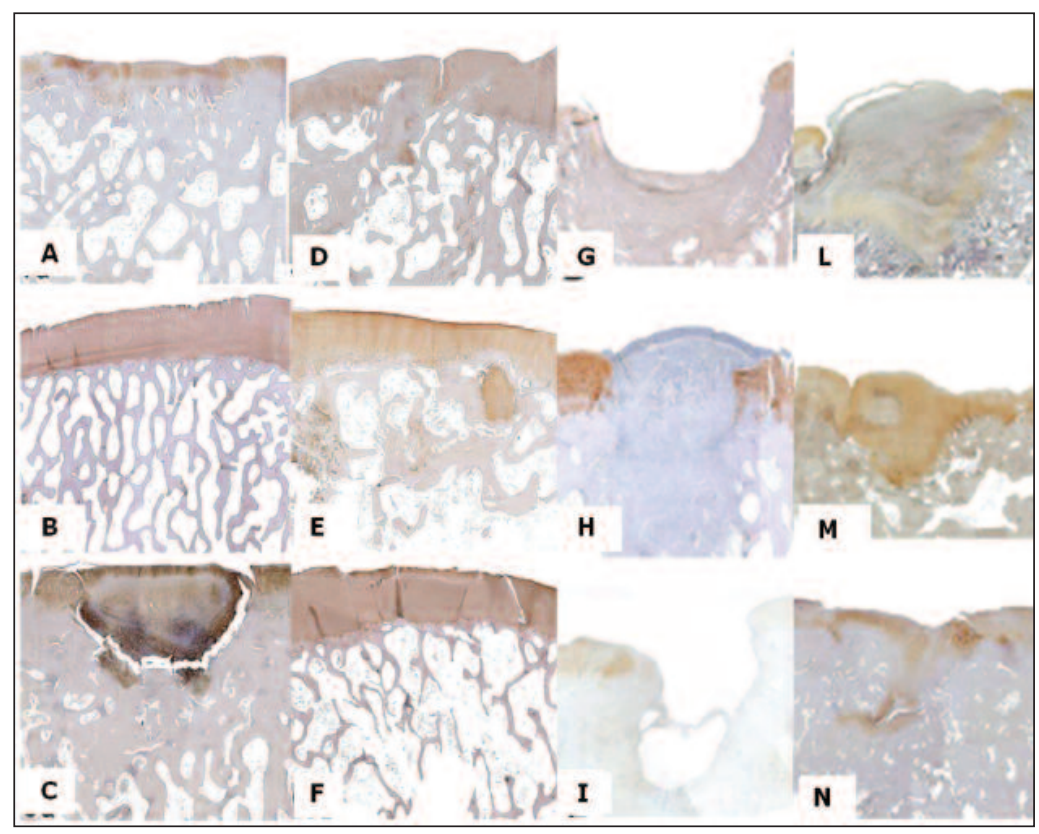

Fig. 6. Femur, sheep. Collagen type II immunostaining. A: ESL-M 12 months after surgery. B: ESL-M 24 months after surgery. C: ED 12 months after surgery. D: ED 24 months after surgery. E: ESL-L 12 months after surgery. F: ESL-L 24 months after surgery. G: ED 1 month after surgery. H: ESL-M 1 month after surgery. I: ED 2 months after surgery. L: ESL-M 2 months after surgery. M: ED 6 months after surgery. N: ESL-M 6 months after surgery.

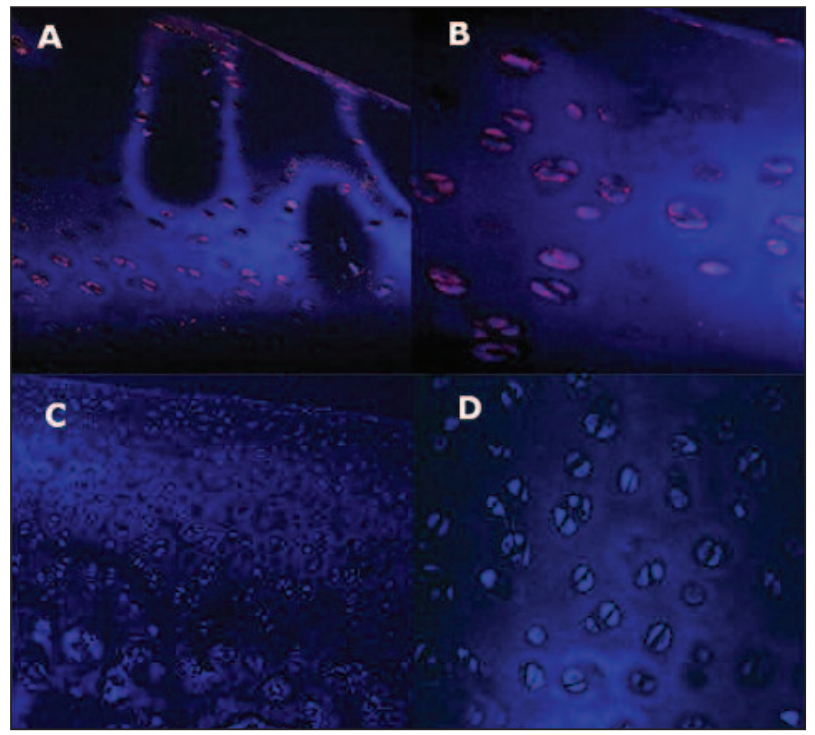

Fig. 7. Femur, sheep. Fluorescent in situ hybridization (FISH). A: FISH performed on ESL engraftments 24 months after surgery. Positive signals in chondrocytes derived from ESL cells. 40X magnification. B: FISH performed on ESL engraftments 24 months after surgery. Positive signals in chondrocytes derived from ESL cells. 60X magnification. C: Normal female adult articular cartilage from the right latfication. C: Normal female adult articular cartilage from the right lat-
eral femoral condyle (negative control). No signals are detected within chondrocytes. 20X magnification. D: Normal female adult articular cartilage from the right lateral femoral condyle (negative control). No signals are detected within chondrocytes. $40 \mathrm{X}$ magnification. extent of calcification, and this process of active calcification and subsequent endochondral ossification seems to be integral to the shape of the joint and, therefore, to the distribution of load.

Immunolocalization of type-II collagen, the main type present in hyaline cartilage $(31,32)$, was detected as from 2 months post-surgery. It was initially mild in both ESL-M and ED samples, becoming more intense in the later ESL grafts as compared to ED samples. Similarly, Safranin-O staining showed higher synthesis of proteoglycans in ESL samples at all times. Several Authors outline the crucial importance of such findings, considering the complex interplay existing between these two components; the collagen fibrils serve to anchor the proteoglycan matrix and contribute to resisting extrinsic forces during loading and the intrinsic swelling that occurs metabolically within the proteoglycan domain (33), while proteoglycans are responsible for the generation of hydrostatic pressure within cartilage matrix, which allows it to counteract the loads transmitted to it from the long bones during normal joint articulation.

Bone remodeling in the ESL-M samples was also superior to that seen in the EDs. Good remodeling of subchondral bone provides the right biomechanical support for hydrostatic compression in the cartilage, which is of critical importance for the differentiation of hyaline-like cartilage (4). This is in agreement with a recent concept that is gaining strong support, namely that subchondral bone and articular cartilage should be considered an interdependent functional unit (34).

To evaluate the influence of load bearing on the regenerative process, a comparison between the ESL engraftments in the medial and the lateral condyles at 12 and 24 months was performed. No significant differences in total histological score were detected between the ESL-M and ESL-L samples, even though the ESL-M scores were better, suggesting a positive influence of higher load on the regeneration process. These results were confirmed by the analysis within periods. At 12 months significantly better bone remo- 
deling was found in the ESL-L as compared to the ESL-M samples. At 24 months, however, the ESL-M samples had better integration of edges, as well as a better total histological score, confirming the crucial importance of edge integration in long-term healing. In conclusion, this study demonstrated that ESL cells, engrafted into osteochondral defects in sheep knee condyles, enhance the regeneration of the articular hyaline cartilage. In addition, it demonstrated the positive influence exerted by load bearing in the host-graft tissue integration. FISH demonstrated that the regenerated tissue was derived from the engrafted ESL cells.

\section{References}

1. Grassel S, Ahmed N. Influence of cellular microenvironment and paracrine signals on chondrogenic differentiation. Front Biosci. 2007;12:4946-4956.

2. Steinert AF, Ghivizzani SC, Rethwilm A, et al. Major biological obstacles for persistent cell-based regeneration of articular cartilage. Arthritis Res Ther. 2007;9:213-228.

3. Mano JF, Reis RL. Osteochondral defects: present situation and tissue engineering approaches. J Tissue Eng Regen Med. 2007;1:261-273.

4. Buckwalter JA, Mankin HJ. Articular cartilage repair and transplantation. Arthritis Rheum. 1998;41:1331-1342.

5. Jackson DW, Scheer MJ, Simon TM. Cartilage substitutes: overview of basic science and treatment options. J Am Acad Orthop Surg. 2001;9:37-52

6. Chen H, Hoemann CD, Sun J, et al. Depth of subchondral perforation influences the outcome of bone marrow stimulation cartilage repair. J Orthop Res. 2011;29:1178-1184.

7. Akens MK, von Rechenberg B, Bittmann P, et al. Long-term in vivo studies of a photo-oxidized bovine osteochondral transplant in sheep. BMC Muskoloskelet Disord. 2001;2:9-20.

8. Jackson DW, Lalor PA, Aberman HM, et al. Spontaneous repair of full-thickness defects of articular cartilage in a goat model. A preliminary study. J Bone Joint Surg Am. 2001;83A: $53-64$.

9. Lietman SA, Miyamoto S, Brown PR, et al. The temporal sequence of spontaneous repair of osteochondral defects in the knees of rabbits is dependent on the geometry of the defect. J Bone Joint Surg Br. 2002;84:600-606.

10. Hurtig MB, Fretz PB, Doige CE, et al. Effects of lesion size and location on equine articular cartilage repair. Can J Vet Res. 1987;52:137-146.

11. Nakajima M, Wakitani S, Harada Y, et al. In vivo mechanical condition plays an important role for appearance of cartilage tissue in ES cell transplanted joint. J Orthop Res. 2008;26:1017.

12. Friedman M, Berasi C, Fox J, et al. Preliminary results with abrasion arthroplasty in the osteoarthritic knee. Clin Orthop Relat Res. 1984;(182):200-205.

13. Gill TJ, Asnis PD, Berkson EM. The treatment of articular cartilage using the microfracture technique. J Orthop Sports Phys Ther. 2006;36:728-738.

14. Wakitani S, Goto T, Pineda SJ, et al. Mesenchymal cell-based repair of large, full-thickness defects of articular cartilage. J Bone Joint Surg Am. 1994;76:579-592.

15. Wakitani S, Aoki H, Harada Y, et al. Embryonic stem cells form articular cartilage, not teratomas, in osteochondral defects of rat joints. Cell Transplant. 2004;13:331-336.

16. Dattena M, Pilichi S, Rocca $S$, et al. Sheep embryonic stemlike cells transplanted in full-thickness cartilage defects. J Tissue Eng Regen Med. 2009;3:175-187.

17. Frosch KH, Drengk A, Krause P, et al. Stem cell-coated titanium implants for the partial joint resurfacing of the knee. Biomaterials. 2006;27:2542-2549.

18. Matsumoto T, Okabe T, Ikawa T, et al. Articular cartilage repair with autologous bone marrow mesenchymal cells. J Cell Physiol. 2010;225:291-295.

19. Undale AH, Westendorf JJ, Yaszemski MJ, et al. Mesenchymal stem cells for bone repair and metabolic bone diseases. Mayo Clin Proc. 2009;84:893-902.

20. Waselau AC, Nadler D, Müller JMV, et al. The effect of cartilage and bone density of mushroom shaped, photooxidized, osteochondral transplants: an experimental study on graft performance in sheep using transplants originating from different species. BMC Muskoloskelet Disord. 2005;6:60-71.

21. Murphy JM, Dixon K, Beck S, et al. Reduced chondrogenic and adipogenic activity of mesenchymal stem cells from patients with advanced osteoarthritis. Arthritis Rheum. 2002; 46:704-713.

22. Murphy JM, Fink DJ, Hunziker EB, et al. Stem cell therapy in a caprine model of osteoarthritis. Arthritis Rheum. 2003;48:3464-3474.

23. Dattena M, Mara L, Bin T AA, et al. Lambing rate using vitrified blastocysts is improved by culture with BSA and hyaluronan. Mol Reprod Dev. 2007;74:42-47.

24. Mara L, Pilichi S, Sanna A, et al. Sexing of in vitro produced ovine embryos by duplex PCR. Mol Reprod Dev. 2004;69: $35-42$.

25. Dattena M, Chessa B, Lacerenza D, et al. Isolation, culture and characterization of embryonic cell lines from vitrified sheep blastocysts. Mol Reprod Dev. 2006;73:31-39.

26. Sanna D, Sanna A, Mara L, et al. Oct4 expression in in-vitroproduced sheep blastocysts and embryonic-stem-like cells. Cell Biol Int. 2009;34:53-60.

27. Caplan A, Elyaderani M, Mochizuki Y, et al. Principles of cartilage repair and regeneration. Clin Orthop Relat Res. 1997;(342):254-269.

28. Sanna E, Sanna MP, Loddo C, et al. Endogenous jaagsiekte sheep retrovirus RNA is expressed by different cell types in ovine foetus and placenta. Eur J Histochem. 2002;46:273280.

29. Tsumaki N, Okada M, Yamashita A. iPS cell technologies and cartilage regeneration. Bone. 2015;70:48-54.

30. Bullough PG, Jagannath A. The morphology of the calcification front in articular cartilage. Its significance in joint function. J Bone Joint Surg Br. 1983;65:72-78.

31. Prockop DJ, Kivirikko KI, Tuderman L, et al. The biosynthesis of collagen and its disorders (first of two parts). N Engl J Med. 1979;301:13-23.

32. Prockop DJ, Kivirikko KI, Tuderman L, et al. The biosynthesis of collagen and its disorders (second of two parts). N Engl J Med. 1979;301:77-85.

33. Miosge N, Hartmann M, Maelicke C, et al. Expression of collagen type I and type II in consecutive stages of human osteoarthritis. Histochem Cell Biol. 2004;122:229-236.

34. Martel-Pelletier J, Pelletier JP. Is osteoarthritis a disease involving only cartilage or other articular tissues? Eklem Hastalik Cerrahisi. 2010;21:2-14. 